\title{
Nutritional interventions to reduce cardiovascular risk factors: an Iranian perspective
}

This article was published in the following Dove Press journal:

Nutrition and Dietary Supplements

28 April 2015

Number of times this article has been viewed

\author{
Nasrin Sharifi' \\ Reza Amani² \\ 'Department of Nutrition, ${ }^{2} \mathrm{Health}$ \\ Research Institute, Department of \\ Nutrition, Faculty of Paramedicine, \\ Ahvaz Jundishapur University of \\ Medical Sciences, Ahvaz, Iran
}

Correspondence: Reza Amani Health Research Institute, Department of Nutrition, Faculty of Paramedicine, Jundishapur University of Medical Sciences, Golestan Blvd, Ahvaz, 61357-I5794, Iran

Tel +989163139856

Fax +98 6I 33738330

Email rezaamani@hotmail.com

\begin{abstract}
Cardiovascular disease (CVD) is the leading cause of death not only in industrialized and developed countries but also in developing societies. Changes in lifestyle of the population living in developing countries, which is due to the socioeconomic and cultural transition, are important reasons for increase in the rate of CVD. This observation has led to extensive body of researches on CVD prevention. In Iran, as a developing country in the Middle East, the increasing incidence of CVD has prompted the health policy-makers to emphasize on nutritional interventions as a part of the main strategies to alleviate the condition. Hence, in this article, we aimed to review the nutritional interventions on preventing CVDs from the perspectives of Iranian lifestyles and dietary patterns using data search sources such as Medline, Google scholar, and Iran doc.
\end{abstract}

Keywords: nutrition, intervention, cardiovascular disease, Iran

\section{Introduction}

Nutrition and dietary patterns play a crucial role in development, prevention, and treatment of chronic diseases, such as cardiovascular disease (CVD), obesity, and diabetes. ${ }^{1}$ Therefore, nutritional interventions have been developed as essential strategies to reduce the incidence of these diseases in developed societies. ${ }^{1}$

CVD is the leading cause of death worldwide, and poor nutrition is one of the major contributors to CVD increase. ${ }^{2}$ In recent decades, taking appropriate lifestyles and implementing healthy nutritional interventions have led to a decline in the CVD mortality rate in developed countries. ${ }^{3,4}$ However, elsewhere in the world where low- and middle-income countries are experiencing rapid socioeconomical development, we are witnessing the increasing incidence of CVDs. ${ }^{5,6}$ In Iran, as a developing country in the Middle East, the increasing incidence of CVD has prompted the health policy-makers to emphasize on nutritional interventions as a part of the main strategies to deal with the condition. ${ }^{7.8}$ So, in this paper, we have reviewed the nutritional interventions aimed at preventing CVDs from the perspectives of Iranian lifestyles and dietary patterns using data search sources such as Medline, Google scholar, and Iran doc. First, we have addressed the comprehensive community studies for preventing CVD and some health targets that have been set by the government in Iran. Thereafter, we will be discussing the nutritional interventions regarding some modifiable risk factors of CVDs in more details.

\section{The large representative nutritional researches and targets for preventing CVDs in Iran}

To prevent and control CVD via reducing its risk factors and improving healthy behaviors in a target population, a community trial entitled Isfahan Healthy Heart 
Program (IHHP) started in 1999 and finished in 2006 in the city of Isfahan, central of Iran. ${ }^{9}$ This program included 10 distinct projects, each targeting different groups. ${ }^{10}$ The interventions comprised public education through the mass media, intersectoral collaboration, community participation, education and involvement of health professionals, marketing and organizational development, legislation and policy development or enforcement, research, and evaluation. ${ }^{11}$ The IHHP promoted healthy nutrition and increased physical activity and conducted tobacco control and stress management activities. ${ }^{12}$ One of the 10 projects of IHHP that was more related to nutritional intervention was Healthy Food for Healthy Community. ${ }^{11}$ The results of this comprehensive community trial shed new light on the risk factors and interventions needed to combat CVD in Iranian population. We presented some results of this program here.

Tehran Lipid and Glucose Study is another comprehensive study with the aim to determine the risk factors for atherosclerosis among Tehran urban population and develop population-based measures to change the lifestyle of the population and prevent incidence of diabetes mellitus and dyslipidemia. ${ }^{13}$ This survey included 17,000 men and women between 3 and 69 years of age from Tehran urban population for the assessment of conventional (ie, smoking, diabetes, and hypertension) and emerging (ie, glucose intolerance, obesity, physical activity, and diet) cardiovascular risk factors. ${ }^{13}$ The results of this study revealed that in Iranian adults, $78 \%$ of men and $80 \%$ of women presented with at least one CVD risk factor. ${ }^{13}$ The percentage of adult women with two or more risk factors was significantly greater than men. ${ }^{13}$ Prevalence of diabetes mellitus, hypertension, obesity, high total cholesterol, low high-density lipoprotein cholesterol (HDL-C), high triglyceride, and smoking was 9.8\%, 20.4\%, 14.4\%, $19.3 \%, 32 \%, 5.3 \%$, and $22.3 \%$, respectively. ${ }^{13}$ In children and adolescents, two or more CVD risk factors were found in $9 \%$ of boys and $7 \%$ of girls. ${ }^{13}$

Childhood and adolescence surveillance and prevention of Adult Noncommunicable disease study was another national study carried out on 21,111 school students aged 6-18 years in 2003-2004. ${ }^{14}$ Among 4,811 subjects of this survey, the most prevalent CVD risk factors were low HDL-C (28\%) followed by hypertriglyceridemia (20.1\%) and overweight (17\%). ${ }^{15}$

Following the alarming increase in CVD incidence in recent decades and including the results of the community surveys, Iranian policy-makers started to establish strategies and targets to deal with CVD in the framework of the Fifth Social-Cultural-Economic Development Plan (2010-2015). ${ }^{16}$
Some of these strategies and targets related to nutrition are as follows:

1. Reducing the prevalence of overweight and obesity in the population of students, youth, and seniors, by at least $10 \%$ by the end of the plan.

2. Increasing the proportion of the population who averagely consume $400 \mathrm{~g}$ of vegetables and fruit per day to $75 \%$ by the end of the program.

3. Reduce the amount of trans fatty acids (TFA) in edible oils to less than $2 \%$ by the end of the program.

4. Reducing the amount of salt in food products to at least $15 \%$ by the end of the program. ${ }^{16}$

\section{The nutritional interventions regarding some modifiable risk factors of CVD}

Based on the recent WHO statistics, the prevalence of important risk factors of CVD, such as diabetes mellitus, hypertension, and obesity is high among Iranian males and females (Figure 1). ${ }^{17}$ Nutritional interventions have important roles in reducing these modifiable risk factors. Hence, in this section, we aimed to address the dietary and nutritional interventions that have beneficial effects on dyslipidemia, hypertension, high blood glucose levels, obesity, early life CVD risk factors, and micronutrient deficiencies.

\section{Dietary fats and oils}

Dietary fats have significant effect on blood lipids, and consequently the risk of CVD. ${ }^{18}$ In Western countries such as the United States, percent of total daily energy intake derived from carbohydrate and fat was $47 \%-51 \%$ and $27 \%-30 \%$, respectively, during 1991-2008. ${ }^{19}$ On the other hand, in Iranian diet, approximately over $60 \%$ of total energy intake comes from carbohydrate and less than $30 \%$ is provided by fat (Figure 2). ${ }^{20-22}$ Therefore, the fat quality rather than the quantity has important effects on lipid profile among Iranians.

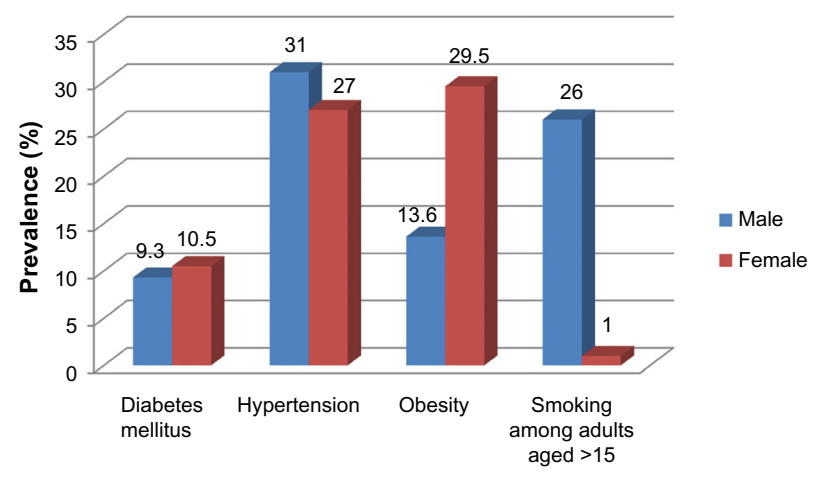

Figure I The prevalence of some important risk factors of CVD among Iranian adults, male and female, based on the World Health Statistics 2014.17 Abbreviation: CVD, cardiovascular disease. 


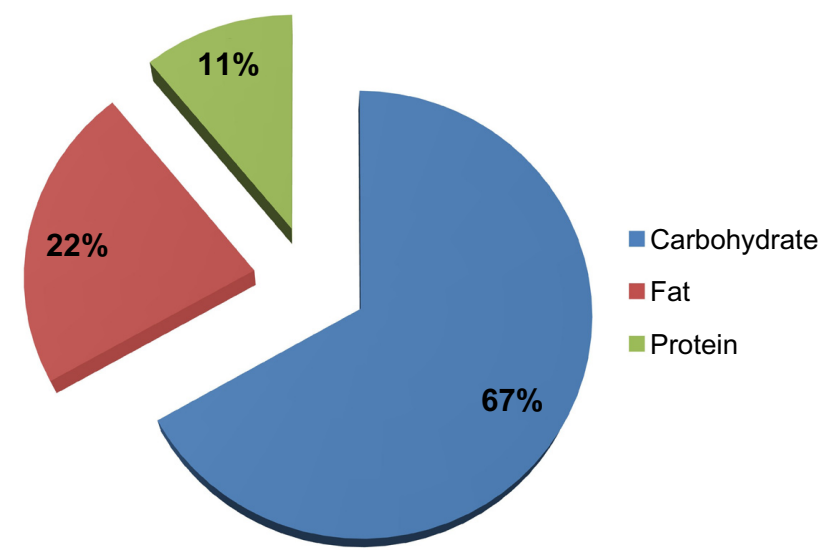

Figure 2 Macronutrients contribution in providing total energy intake in Iranian population during the years 200 I-2006 based on the food balance sheet of Iran ${ }^{80}$

Healthy oils are those that contain no TFA, are low in saturated fatty acids, and are high in mono- and polyunsaturated fatty acids. ${ }^{2}$

In recent decades, consumption of hydrogenated vegetable oils was considerably increased for cooking in Iranian dietary pattern. ${ }^{21}$ This type of oil is the major sources of saturated fatty acids and TFA. ${ }^{23}$ The adverse effects of TFA on CVD risk factors have been shown in Table 1. In a casecontrol study conducted in patients with coronary artery disease, Amani et $\mathrm{al}^{24}$ showed that consumption of hydrogenated fats increased the risk of CVD more than two times

Table I Adverse effects of TFA on cardiovascular disease risk factors

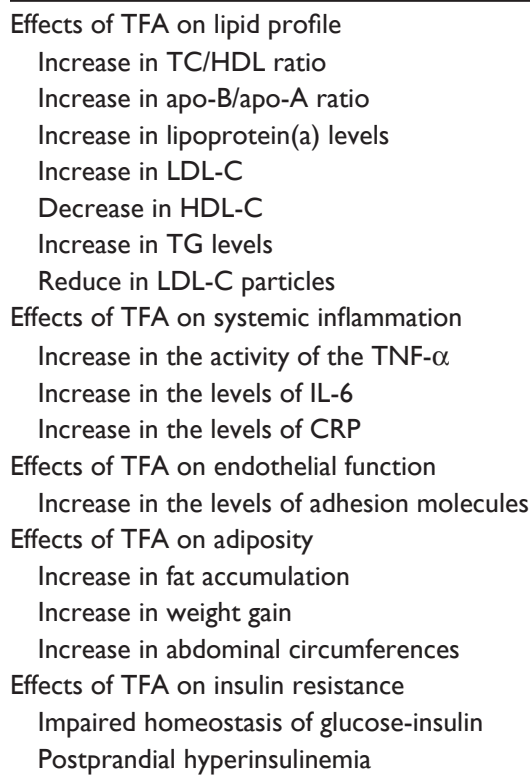

Note: Based on the review study by Mozaffarian et al. ${ }^{93}$

Abbreviations: apo-A, apolipoprotein A; apo-B, apolipoprotein B; CRP, C-reactive protein; HDL-C, high-density lipoprotein cholesterol; IL-6, interleukin 6; LDL-C, low-density lipoprotein cholesterol; TC, total cholesterol; TFA, trans fatty acid; TG, triglyceride; TNF- $\alpha$, tumor necrosis factor $\alpha$. (odds ratio $=2.12$ [95\% confidence interval 1.23-3.64]). Mozaffarian et $\mathrm{al}^{21}$ also showed that partially hydrogenated oils are extensively being used for cooking in Iranian homes with average per-person intake of $14 \mathrm{~g} / 1,000 \mathrm{kcal}$. TFA accounted for $33 \%$ of fatty acids in these products, or $4.2 \%$ of total calories consumed (12.3 g/day). ${ }^{21}$ However, following the promotion of new nutritional education programs delivered at the national level, consumption of hydrogenated fats has been decreasing gradually while consumption of soy and sunflower oils has increased in the households during recent years. ${ }^{25}$ Unfortunately, hydrogenated fats are still being used widely in food industries and confectionary products. ${ }^{26}$ It is a reminder to the health officials to consider the reduction of TFAs in oil products as a crucial strategy to prevent CVD in Iran. In North America and Europe, a dramatic decline in the trans fat contents of food products occurred between 2005 and 2010. This decrease was due to changes in federal labeling requirements for packaged foods, local bans on the use of partially hydrogenated fats, and popular pressure to remove partially hydrogenated fat from the food supply. ${ }^{27,28}$

The other sources of the saturated fatty acids in Iranian diets are red meat and full-fat dairies. ${ }^{21,24}$ Consumption of full-fat yoghurts was associated with significant risk of CVD $(\mathrm{OR}=2.35$ [95\% confidence interval 1.32-4.18]) in a sample of Iranian patients with coronary artery disease. ${ }^{24}$ Consumption of fatty lamb as a commonly preferred meat in Iranian families is associated with dyslipidemia. ${ }^{20}$ Encouraging families to use leaner meats can improve the dietary habits.

The vegetable liquid oils mostly consumed in households are soybean and sunflower oils containing higher contents of $n-6$ polyunsaturated fatty acids. ${ }^{20,21}$ Olive oil, as the main source of mono-unsaturated fatty acids that has beneficial effect on blood lipids, ${ }^{29}$ is consumed at lower priority due to its higher costs. ${ }^{30,31}$

In Iranian traditional dietary pattern, consumption of fish, and therefore, seafood-derived $n-3$ fatty acids, is very low especially in central parts of the country that are far from the sea. ${ }^{21,32}$ Thus, vegetable oils mainly provide $n-3$ fatty acids in the diet. ${ }^{21}$

In summary, replacement of hydrogenated oils with vegetable oils having more $n-3$ fatty acids might help reduce CVD incidence among Iranians. Additionally, it is basically crucial to develop affordable supplies of healthy oils at community level.

\section{Dietary sodium}

There is considerable evidence on causal relation between salt intake and high blood pressure. ${ }^{33-35}$ The estimated 
age-standardized prevalence of hypertension was 34\% in the Iranian adult population ${ }^{36}$ and is almost similar to the prevalence of hypertension in some Western countries. ${ }^{37,38}$ The average amount of salt intake is estimated to be $12 \mathrm{~g}$ /day in Iranians. ${ }^{39} \mathrm{O}^{\prime}$ Flaherty et $\mathrm{al}^{40}$ showed that reducing salt consumption by $1 \mathrm{~g}$ /day and increasing fruit and vegetable intake by one portion per day could result in approximately 12,500 fewer CVD deaths in the United Kingdom. Moreover, a daily reduction of $3 \mathrm{~g}$ in salt intake (from 8.6 to $5.6 \mathrm{~g} /$ day) might generate approximately 6,600 fewer CVD deaths. These findings emphasize the role of the implemented strategies to reduce salt intake in order to achieve less mortality rate from CVD among populations.

Main dietary sources of salt in Iranian diet are canned, processed, and fast foods as well as the salt in the bread composition and the table uses. ${ }^{39}$

Bread is one of the staple foods in Iran, and unfortunately, bakeries are addicted to adding salt to their products. ${ }^{41}$ Hence, to reduce the incidence of hypertension, it is necessary that the government and nongovernmental organizations take a serious action to improve the quality of the bread products.

Based on the traditional Iranian dietary habits, salt plays an important role in creating taste and flavor of the food. Adding salt before tasting is a habit prevalent during meals by Iranians. ${ }^{42}$ Therefore, educational programs seem to be helpful for overcoming the high salt intake. The goal for the daily salt intake in Iran is set to be less than $5 \mathrm{~g} /$ day. $^{39}$

\section{Dietary patterns}

Comparing how different types of dietary patterns could affect CVD risks is suggested by Institute of Medicine (IOM) for the prevention of disease in all countries. ${ }^{2}$ In Iran, three types of dietary patterns are identified from the recent studies: ${ }^{43-45}$ Western type, high-animal fats diet, and Iranian traditional diet. Western diet is characterized by high intake of sweets, carbonated beverages, fast foods, junk foods, salty nuts/seeds, and canned foods. High-animal fat diet is described as high intake of animal fats, whole dairy products, eggs, and organ meats. The traditional diet was characterized by high intake of potatoes, beans, red meat, eggs, and dried fruits. ${ }^{22,43,45}$

The western and animal dietary patterns have adverse effects on CVD risk. ${ }^{43,44}$ However, Iranian traditional dietary pattern has its pros and cons in terms of the CVD prevention. As mentioned earlier, the majority of energy intake comes from carbohydrates. ${ }^{20}$ Bread and white rice are two staple foods consumed in Iran. ${ }^{41,46}$ High refined carbohydrate intake from these food items is related to hypertriglyceridemia, decreased HDL levels, and formation of small, dense low-density lipoprotein cholesterol particles leading to CVD. ${ }^{47}$ Additionally, high-carbohydrate/low-fat dietary patterns lead to increased prevalence of other CVD risk factors such as abdominal obesity and insulin resistance known as the components of the metabolic syndrome. ${ }^{48}$

In Iranian traditional dietary pattern, consumption of fatty lambs is prevalent and reported to be associated with dyslipidemia. ${ }^{20}$ Moreover, frying is the predominant cooking method among Iranians. ${ }^{42}$

One of the advantages of the Iranian traditional dietary patterns is high consumption of beans and legumes. Legumes are low-glycemic index, low energy-dense foods that contain high amounts of dietary fiber, vegetable proteins, oligosaccharides, and other bioactive compounds. ${ }^{49}$ The types of legumes that are mostly consumed in Iran include lentils, peas, chickpeas, and different kinds of beans. ${ }^{50,51}$ In a crosssectional study, consumption of legumes was inversely associated with inflammatory biomarkers such as high-sensitive c-reactive protein, tumor necrosis factor alpha, interleukin 6 , and the adhesion molecules in a sample of women. ${ }^{50}$ The cellular adhesion molecules, which are expressed on the endothelial membranes in response to several inflammatory stimuli, can lead to the adhesion of circulating leukocytes to the endothelial cells. ${ }^{52}$ This is an important step in initiation and aggravation of atherosclerotic lesions. ${ }^{52}$

Traditionally, soy bean is consumed less by Iranians. However, it seems that following the development of the nutritional education programs and explaining the beneficial effects of soybeans, acceptance of consuming soy products is increasing. ${ }^{53}$ Soy bean contains isoflavones that might be responsible, in part, in lowering the risk of CVD and atherosclerosis through decreasing total and low-density lipoprotein cholesterol and increasing HDL-C concentrations. ${ }^{54}$

The other advantage of Iranian traditional dietary pattern is consumption of dried fruits and berries. Dried fruits contain a high amount of nutrients such as potassium, magnesium, and folate that have important roles in increasing diet quality and reducing blood pressure. ${ }^{55}$ As an example of the effects of dried berries on metabolic biomarkers of CVD, Moazen et $\mathrm{al}^{56}$ and Amani et $\mathrm{al}^{57}$ in a placebo-controlled randomized clinical trial showed that supplementation with freeze-dried strawberries improved total cholesterol, antioxidant status, reduced lipid peroxidation, and inflammatory response in patients with type 2 diabetes.

Drinking tea is another dietary habit among Iranians that might have a protective effect on CVD risk via the antioxidant content of the tea. In a case-control study, drinking tea 
was significantly associated with lower risk of coronary events. $^{24}$

Having nuts and seeds as snacks is another common dietary habit among Iranians. ${ }^{58}$ However, taking into account the calorie and salt contents of such foods, they may have some beneficial effects on hypertension and blood lipid disorders. ${ }^{59,60}$ The results of a study as a part of IHHP showed that the frequency of nuts consumption was inversely associated with dyslipidemia especially for those who had consumed nuts four or more times weekly. ${ }^{60}$

\section{Fruits and vegetables}

Low consumption of fruits and vegetables has been reported in Iranians. ${ }^{7}$ The increasing cost of vegetables/fruits, may decrease their consumption. ${ }^{7}$ Fruits and vegetables contain high amount of fibers, vitamins, minerals, and antioxidants that may exert protection against CVD. ${ }^{61}$ The results of previous studies showed that higher consumption of fruits and vegetables is associated with lower rates of obesity, hypertension, and diabetes as well as lower serum levels of high-sensitive C-reactive protein and malondialdehyde and higher levels of total antioxidant capacity. ${ }^{62,63}$ To prevent hypertension and CVD, it is recommended to consume at least five servings of fruits and vegetables a day. ${ }^{64}$

\section{Nutritional and behavioral interventions}

to reduce over weight and obesity

Obesity is an independent risk factor for CVD. ${ }^{65}$ In Iran, the prevalence of overweight and obesity is $42.8 \%$ in men and $57.0 \%$ in women. ${ }^{66}$ Also, obesity is more common among women than men (Figure 1). ${ }^{66}$ In order to address the appropriate interventions for obesity prevention and treatment, it is necessary to detect individuals who have greater risk of obesity. This can be achieved by developing local cut-off points for defining overweight and obesity at the national level. For example, in a study of 637 Iranian females, it was indicated that a part of subjects with lower body mass index tend to have higher fat percentage and they might represent a different subclass as overfat thin. ${ }^{67}$

Excess energy intake is one of the key contributors to obesity. ${ }^{68}$ As a practical problem, lack of relevant data limits policy-makers to focus on dietary components to conduct effective interventions aimed at reducing the burden of obesity.

On the other hand, defining obesity as an Eco-Bio-PsychoSocio-Cultural issue would open new insights to ecological and sociocultural approaches in addition to the known biological (genetics) and psychological factors. Ecological approach emphasizes on specific needs of some countries or regions that are exposed to extreme weather conditions that make people stay away from outdoor activities. Moreover, in this regard, there might be local prevalent dietary habits like having more fried foods and availability of food sources such as dates and sweets influencing the calorie balance.

These approaches need intersectoral collaborations dealing with obesity. As a result, a wide range of strategies and programs should be planned to reduce the prevalence of obesity. Some of these programs include influencing the food supply to make healthy choices easier; reducing the marketing of energy-dense foods and sugar-sweetened beverages, especially for children; developing nationwide programs in multiple settings; influencing urban environments and transport systems to promote physical activity; increased communications on healthy eating habits, and improved health services to manage overweight and/or obese subjects. ${ }^{69}$

\section{Nutritional interventions regarding early life factors and subsequent risk of CVD}

Based on cohort studies, there is growing evidence in both developing and developed countries that fetal and early childhood periods is important in the onset of CVDs in later life (Figure 3). ${ }^{70,71}$ Undernutrition, low birth weight, and lack of breastfeeding are among the main factors that predispose a child to CVD in adulthood. ${ }^{72}$ In recent years, after the promotion of health services in Iran, the prevalence of undernutrition under 5 years has significantly decreased. ${ }^{73}$ However, the rate of low birth weight has shown no changes. ${ }^{74}$ Based on the results of the study by Jafari et al, ${ }^{74}$ low socioeconomic status, mothers' low educational levels, and poor nutritional status are among the reasons for unchanged low-birth weight rates in Iran. Additionally, based on WHO 2014 statistics, only $28 \%$ of infants in Iran have exclusively been breastfed until 6 months of age. ${ }^{17}$ Therefore, it seems that more focused nutritional education programs should be delivered to young women and mothers to improve their nutritional awareness during reproductive age and pregnancy. ${ }^{75}$

On the other hand, childhood and adolescent obesity is associated with multiple risk factors for CVD including hyperlipidemia, high blood pressure, impaired glucose tolerance and high insulin levels, as well as metabolic syndrome. ${ }^{76}$ The prevalence of overweight and obesity among Iranian children and adolescents has increased during recent years. ${ }^{77}$ The national nutritional interventions should target some unhealthy dietary habits and lifestyles among this group. The results of a nationwide cross-sectional study among adolescents aged 11-18 years showed that regular extracurricular 


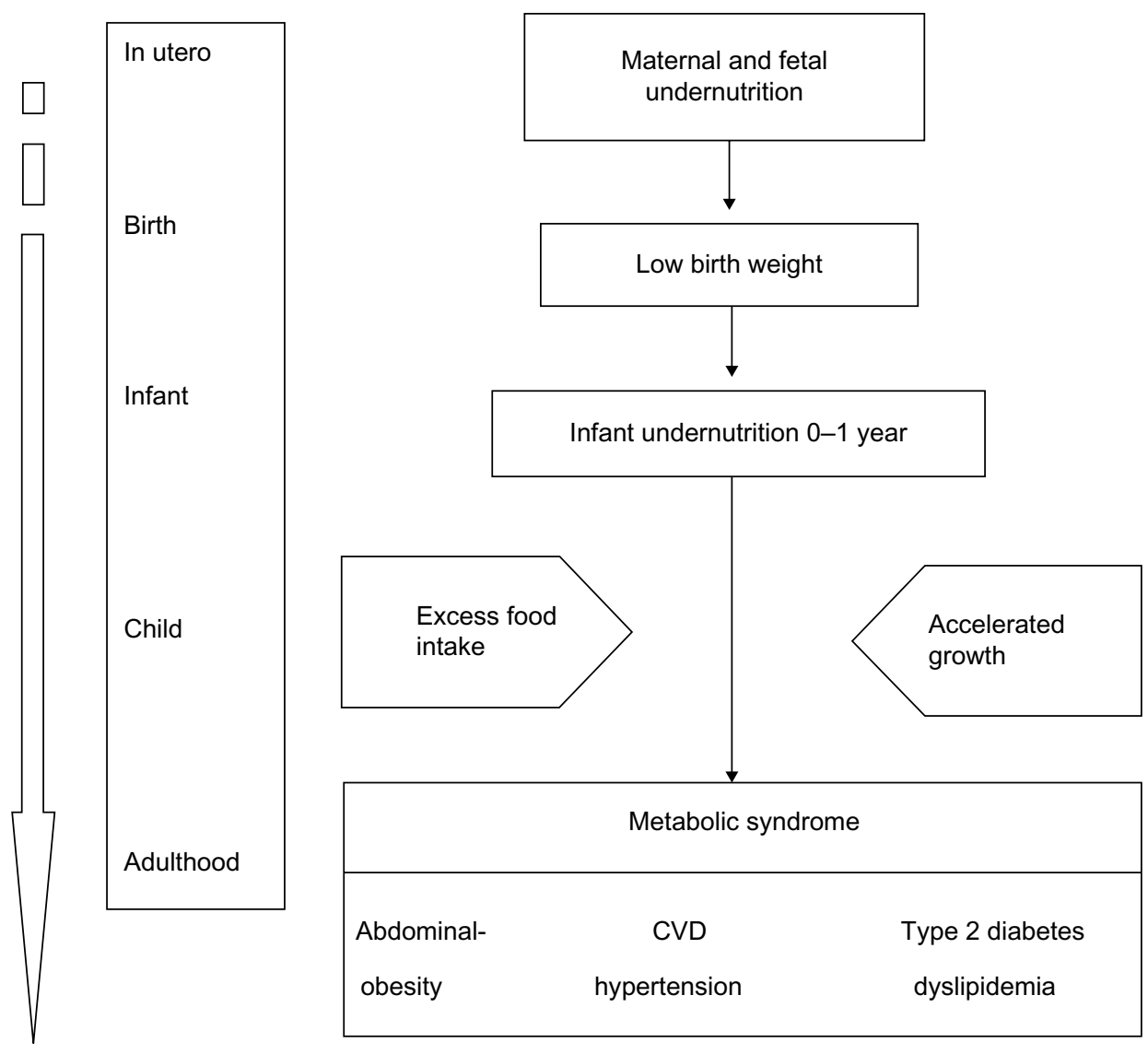

Figure 3 Developmental origins of health and diseases. Abbreviation: CVD, cardiovascular disease.

sports activities were significantly lower and the time spent watching television was significantly higher in overweight or obese than the nonobese subjects. ${ }^{78}$ Additionally, a significant linear association was shown between the frequency of consumption of rice, bread, pasta, fast foods, and fatty/ salty snacks and body mass index. ${ }^{78}$ Also, a significant linear association was shown between adolescents' dyslipidemia and the frequency of intake of hydrogenated fats, fast foods, cheese puffs, and potato chips. ${ }^{20}$

It seems that there is a lack of applied educational programs on healthy nutrition in schools and mass media in Iran. Furthermore, providing more facilities for sports will be helpful to improve physical activity levels at community levels. ${ }^{79}$

\section{Micronutrient deficiency among Iranians} that might predispose them to CVD

Deficiencies of riboflavin, folate, and vitamin D among Iranian population might increase the risk of CVD. Based on the food balanced sheet data between 2001 and 2006, the intake of riboflavin and other B vitamins such as B6 and folate were estimated to be low among Iranians. ${ }^{80}$ About $40 \%-50 \%$ of population was estimated to have riboflavin deficiency ${ }^{80}$
Age-adjusted prevalence of low serum folate levels was 98.67\% in men and $97.92 \%$ in women. ${ }^{81}$ Vitamin B deficiencies may influence the CVD risk through the increased serum homocysteine levels as a known risk factor. ${ }^{82}$

The results of several studies in Iran showed that the prevalence of vitamin D deficiency is very high. ${ }^{83-85}$ Poor sun exposure, religious issues regarding clothing, air pollution, and lack of vitamin $\mathrm{D}$ fortification programs can explain the high prevalence of vitamin D deficiency in Iran and other similar Middle East countries. ${ }^{83}$ On the other hand, the evidence from epidemiological studies showed the association between vitamin D deficiency and increased risk of CVD and its risk factors such as hypertension, diabetes, and metabolic syndrome..$^{86-88}$ The results of some trials have shown that improved status of vitamin D is associated with reduction in CVD risk factors, ${ }^{89-91}$ although the protective effects of vitamin D in CVD are controversial and need to be confirmed in further randomized clinical trials. ${ }^{92}$

Therefore, changing dietary habits through applied education, proper supplementation programs, and food fortification could alleviate prevalent nutritional deficiencies all regarded as the most important strategies to reduce CVDs in Iran. 


\section{Summary}

Based on the issues discussed above, nutritional strategies for future interventions that might prevent CVD in Iran are summarized below:

- Nutritional education is one of the important strategies for preventing CVD that could be delivered to different groups of population through mass media, school curriculums, dietary counseling, booklets, continuing medical education programs, etc.

- Limit using hydrogenated oils containing TFA in food industries and confectionary products.

- Replacing the hydrogenated oils with healthier vegetable oils that include more $n-3$ fatty acids and developing affordable supplies of healthy oils.

- Reducing the sodium content of the staple foods such as bread.

- Producing whole-grain products with acceptable quality.

- Maintaining subsidized plans on healthy foods such as dairies, fruits, vegetables, and fish.

- Appropriate labeling of the food products in terms of energy, fats, sodium, TFA, and fiber contents.

- Reducing the prevalence of low-birth weight infants through promoting mothers' nutritional status.

- Promoting breastfeeding of infants until 6 months of age.

- Introducing half-portion size and healthier options in fast food restaurants.

- Fortification of food products with nutrients that have been reported deficient or low in dietary pattern of population.

\section{Conclusion}

For implementing nutritional intervention to reduce CVDs' risk factors in Iranians, comprehensive collaborations are needed between political, agricultural, economical, social, and health sectors alongside the research and educational organizations. Both governmental bodies and nongovernmental organizations should be involved.

\section{Future research}

Future researches are required to evaluate the effectiveness of the nutritional interventions to reduce CVD incidence at population level. There is a lack of well-designed cohort studies addressing the main CVD risk factors. We also need to define applied cut-off points for the main risk factors based on national or local studies that are more relevant and precise to our population.

Epigenetics is another field of study to find out the genetic basis of CVDs in Iranians.
As indicated in ancient Traditional Persian Medicine books (such as The Canon of Medicine by Avicenna, 980-1037 AD) for centuries, understanding the effect of foods and not just the individual nutrients or supplements, on both preventing and curing the heart disease and hyperlipidemias could be regarded as leading fields of study in the near future.

\section{Author contributions}

All authors have contributed to the conception and design, acquisition of data, analysis and interpretation of data of this manuscript. All authors have drafted or revised the manuscript. The final version of the manuscript has been approved by all the authors where they agree to be accountable for all aspects of the work ensuring that questions related to the accuracy or integrity of any part of the work are appropriately investigated and resolved.

\section{Disclosure}

The authors declare that they have no conflicts of interest.

\section{References}

1. Amine E, Baba N, Belhadj M, et al. Diet, Nutrition and the Prevention of Chronic Diseases: Report of a Joint WHO/FAO Expert Consultation Geneva: World Health Organization; 2002.

2. Kelly BB, Fuster V. Promoting Cardiovascular Health in the Developing World: A Critical Challenge to Achieve Global Health. Washington, DC: National Academies Press; 2010.

3. Laatikainen T, Critchley J, Vartiainen E, Salomaa V, Ketonen M, Capewell S. Explaining the decline in coronary heart disease mortality in Finland between 1982 and 1997. Am J Epidemiol. 2005;162(8): 764-773.

4. Unal B, Critchley JA, Capewell S. Explaining the decline in coronary heart disease mortality in England and Wales between 1981 and 2000 Circulation. 2004;109(9):1101-1107.

5. Hu FB. Globalization of food patterns and cardiovascular disease risk. Circulation. 2008;118(19):1913-1914.

6. Dangour AD, Uauy R. Nutrition challenges for the twenty-first century. Br J Nutr. 2006;96(S1):S2-S7.

7. Ghassemi H, Harrison G, Mohammad K. An accelerated nutrition transition in Iran. Public Health Nutr. 2002;5(1a):149-155.

8. Lozano R, Naghavi M, Foreman K, et al. Global and regional mortality from 235 causes of death for 20 age groups in 1990 and 2010: a systematic analysis for the Global Burden of Disease Study 2010. Lancet 2013;380(9859):2095-2128

9. Sarraf-Zadegan N, Sadri G, Malek Afzali H, et al. Isfahan Healthy Heart Program: a comprehensive integrated community-based program for cardiovascular disease prevention and control. Acta Cardiol. 2003;58(4):309-320.

10. Rabiei K, Kelishadi R, Sarrafzadegan N, et al. Isfahan Healthy Heart Program: evaluation of comprehensive, community-based interventions for non-communicable disease prevention. Prev Contr. 2006;2(2) 73-84.

11. Sarrafzadegan N, Kelishadi R, Esmaillzadeh A, et al. Do lifestyle interventions work in developing countries? Findings from the Isfahan Healthy Heart Program in the Islamic Republic of Iran. Bull World Health Organ. 2009;87(1):39-50. 
12. Mohammadifard N, Kelishadi R, Safavi M, et al. Effect of a communitybased intervention on nutritional behaviour in a developing country setting: the Isfahan Healthy Heart Programme. Public Health Nutr. 2009;12(09):1422-1430.

13. Azizi F, Rahmani M, Emami H, et al. Cardiovascular risk factors in an Iranian urban population: Tehran lipid and glucose study (phase 1). Soz Präventivmed. 2002;47(6):408-426.

14. Kelishadi R, Ardalan G, Gheiratmand R, Adeli K, Delavari A, Majdzadeh R. Paediatric metabolic syndrome and associated anthropometric indices: the CASPIAN Study. Acta Paediatr. 2006;95(12): 1625-1634.

15. Kelishadi R, Gheiratmand R, Ardalan G, et al; CASPIAN Study Group. Association of anthropometric indices with cardiovascular disease risk factors among children and adolescents: CASPIAN Study. Int J Cardiol. 2007; 117(3):340-348.

16. Vosoogh Moghaddam A, Damari B, Alikhani S, et al. Health in the 5th 5-years development plan of Iran: main challenges, general policies and strategies. Iran J Public Health. 2013;42(Suppl 1):42.

17. World Health Organization. World Health Statistics 2014. Geneva, Switzerland: World Health Organization; 2014:120.

18. Astrup A. Dietary fat is a major player in obesity - but not the only one. Obes Rev. 2002;3(2):57-58.

19. Vadiveloo M, Scott M, Quatromoni P, Jacques P, Parekh N. Trends in dietary fat and high-fat food intakes from 1991 to 2008 in the Framingham Heart Study participants. Br J Nutr. 2014;111(4): 724-734.

20. Kelishadi R, Pour MH, Zadegan NS, et al. Dietary fat intake and lipid profiles of Iranian adolescents: Isfahan Healthy Heart Program heart health promotion from childhood. Prev Med. 2004;39(4): 760-766.

21. Mozaffarian D, Abdollahi M, Campos H, Houshiarrad A, Willett W. Consumption of trans fats and estimated effects on coronary heart disease in Iran. Eur J Clin Nutr. 2007;61(8):1004-1010.

22. Esmaillzadeh A, Azadbakht L. Food intake patterns may explain the high prevalence of cardiovascular risk factors among Iranian women. J Nutr. 2008;138(8):1469-1475.

23. Lichtenstein AH, Erkkilä AT, Lamarche BT, Schwab US, Jalbert SM, Ausman LM. Influence of hydrogenated fat and butter on CVD risk factors: remnant-like particles, glucose and insulin, blood pressure and C-reactive protein. Atherosclerosis. 2003;171(1):97-107.

24. Amani R, Noorizadeh M, Rahmanian S, Afzali N, Haghighizadeh MH. Nutritional related cardiovascular risk factors in patients with coronary artery disease in IRAN: a case-control study. Nutr J. 2010; 9(70):21184687.

25. Mohammadifard N, Toghianifar N, Sajjadi F, et al. Improvement of dietary oil consumption following a community trial in a developing country: the role of translational research in health promotion. ARYA Atheroscler. 2013;9(1):29.

26. Peymani P, Joulaie H, Zamiri N, et al. Iran's experience on reduction of trans-fatty acid content in edible oils. Middle East J Sci Res. 2012;11(9): 1207-1211.

27. Lichtenstein AH. Dietary trans fatty acids and cardiovascular disease risk: past and present. Curr Atheroscler Rep. 2014;16(8):1-7.

28. Menaa F, Menaa A, Menaa B, Tréton J. Trans-fatty acids, dangerous bonds for health? A background review paper of their use, consumption, health implications and regulation in France. Eur J Nutr. 2013;52(4): 1289-1302.

29. Estruch R, Ros E, Salas-Salvadó J, et al; PREDIMED Study Investigators. Primary prevention of cardiovascular disease with a Mediterranean diet. N Engl J Med. 2013;368(14):1279-1290.

30. Jafari M, Kadivar M, Keramat J. Detection of adulteration in Iranian olive oils using instrumental (GC, NMR, DSC) methods. J Am Oil Chem Soc. 2009;86(2):103-110.

31. Misra A, Singhal N, Khurana L. Obesity, the metabolic syndrome, and type 2 diabetes in developing countries: role of dietary fats and oils. J Am Coll Nutr. 2010;29(Suppl 3):289S-301S.
32. Amani R, Boustani F. Prevalence of obesity and dietary practices in Jondi-Shapour University female personnel, Ahvaz, Iran. Pak J Med Sci. 2008;24(5):748-752.

33. He FJ, MacGregor GA. Salt, blood pressure and cardiovascular disease. Curr Opin Cardiol. 2007;22(4):298-305.

34. Khaw KT, Bingham S, Welch A, et al. Blood pressure and urinary sodium in men and women: the Norfolk Cohort of the European Prospective Investigation into Cancer (EPIC-Norfolk). Am J Clin Nutr. 2004;80(5):1397-1403.

35. Meneton P, Jeunemaitre X, de Wardener HE, Macgregor GA. Links between dietary salt intake, renal salt handling, blood pressure, and cardiovascular diseases. Physiol Rev. 2005;85(2):679-715.

36. Naghavi M, Pourmalek F, Shahraz S, Jafari N, Delavar B, Motlagh ME. The burden of injuries in Iranian children in 2005. Popul Health Metr. 2010;8:5.

37. Centers for Disease Control and Prevention (CDC). Vital signs: prevalence, treatment, and control of hypertension - United States, 1999-2002 and 2005-2008. MMWR Morb Mortal Wkly Rep. 2011;60(4):103.

38. Wolf-Maier K, Cooper RS, Banegas JR, et al. Hypertension prevalence and blood pressure levels in 6 European countries, Canada, and the United States. JAMA. 2003;289(18):2363-2369.

39. Alireza Khosravi M, Reza Malekzadeh M, Sarrafzadegan N. Advocacy strategies and action plans for reducing salt intake in Iran. Arch Iran Med. 2012;15(5):320.

40. O'Flaherty M, Flores-Mateo G, Nnoaham K, Lloyd-Williams F, Capewell S. Potential cardiovascular mortality reductions with stricter food policies in the United Kingdom of Great Britain and Northern Ireland. Bull World Health Organ. 2012;90(7):522-531.

41. Talaei M, Mohammadifard N, Khaje MR, et al. Healthy bread initiative: methods, findings, and theories - Isfahan Healthy Heart Program. J Health Popul Nutr. 2013;31(1):49.

42. Farahani M, Mohammadi E, Ahmadi F, Maleki M, Hajizadeh E. Cultural barriers in the education of cardiovascular disease patients in Iran. Int Nurs Rev. 2008;55(3):360-366

43. Mohammadifard N, Sarrafzadegan N, Nouri F, et al. Using factor analysis to identify dietary patterns in Iranian adults: Isfahan Healthy Heart Program. Int J Public Health. 2012;57(1):235-241.

44. Alizadeh M, Mohtadinia J, Pourghasem-Gargari B, Esmaillzadeh A. Major dietary patterns among female adolescent girls of Talaat intelligent guidance school, Tabriz, Iran. Iran Red Crescent Med J. 2012;14(7):436.

45. Esmaillzadeh A, Kimiagar M, Mehrabi Y, Azadbakht L, Hu FB, Willett WC. Dietary patterns and markers of systemic inflammation among Iranian women. J Nutr. 2007;137(4):992-998.

46. Khosravi-Boroujeni H, Sarrafzadegan N, Mohammadifard N, et al. White rice consumption and CVD risk factors among Iranian population. J Health Popul Nutr. 2013;31(2):252.

47. Dreon D, Fernstrom H, Miller B, Krauss R. Low-density lipoprotein subclass patterns and lipoprotein response to a reduced-fat diet in men. FASEB J. 1994;8(1):121-126.

48. Amani R. Obesity prevalence and its nutritional related lifestyle pattern in Jundi-Shapour University female staff, Ahvaz, Iran. Int J Endocrinol Metab. 2007;5(3):135-140.

49. Messina MJ. Legumes and soybeans: overview of their nutritional profiles and health effects. Am J Clin Nutr. 1999;70(3): $439 \mathrm{~s}-450 \mathrm{~s}$.

50. Esmaillzadeh A, Azadbakht L. Legume consumption is inversely associated with serum concentrations of adhesion molecules and inflammatory biomarkers among Iranian women. J Nutr. 2012;142(2):334-339.

51. Sajjadi F, Gharipour M, Mohammadifard N, Nouri F, Maghroun M, Alikhasi H. Relationship between legumes consumption and metabolic syndrome: findings of the Isfahan Healthy Heart Program. ARYA Atheroscler. 2014;10(1):18-24.

52. Blankenberg S, Rupprecht HJ, Bickel C, et al. Circulating cell adhesion molecules and death in patients with coronary artery disease. Circulation. 2001;104(12):1336-1342. 
53. Shurtleff W, Aoyagi A. History of Soybeans and Soyfoods in the Middle East: Extensively Annotated Bibliography and Sourcebook. Lafayette, CA: Soyinfo Center; 2008.

54. Ra A, Zand-Moghaddam A. Effects of soy protein isoflavones on serum lipids, lipoprotein profile and serum glucose of hypercholesterolemic rabbits. Int J Endocrinol Metab. 2005;2:87-92.

55. Keast DR, O'Neil CE, Jones JM. Dried fruit consumption is associated with improved diet quality and reduced obesity in US adults: National Health and Nutrition Examination Survey, 1999-2004. Nutr Res. 2011;31(6):460-467.

56. Moazen S, Amani R, Homayouni RA, Shahbazian H, Ahmadi K, Taha JM. Effects of freeze-dried strawberry supplementation on metabolic biomarkers of atherosclerosis in subjects with type 2 diabetes: a randomized double-blind controlled trial. Ann Nutr Metab. 2012;63(3):256-264.

57. Amani R, Moazzen S, Shahbazian H, Ahmadi Ankali K, Homayouni Rad A, Jalali M. Effects of freeze-dried strawberries on lipid profile and glycated hemoglobin in subjects with type 2 diabetes: a double blind randomized control trial. Iran J Nutr Sci Food Tech. 2013;8(3):189-200.

58. Sedaqat F, Rabiei S, Faria S, Rastmanesh R. Correlates of snacking with stress and depression in obese and non-obese women. J Obes Weight Loss Ther. 2013;3(161):2.

59. Yazdekhasti N, Mohammadifard N, Sarrafzadegan N, Mozaffarian D, Nazem M, Taheri M. The relationship between nut consumption and blood pressure in an Iranian adult population: Isfahan Healthy Heart Program. Nutr Metab Cardiovasc Dis. 2013;23(10):929-936.

60. Askari G, Yazdekhasti N, Mohammadifard N, et al. The relationship between nut consumption and lipid profile among the Iranian adult population; Isfahan Healthy Heart Program. Eur J Clin Nutr. 2013;67(4): 385-389.

61. Rodriguez-Casado A. The health potential of fruits and vegetables phytochemicals: notable examples. Crit Rev Food Sci Nutr. In Press 2014.

62. Berciano S, Ordovás JM. Nutrition and cardiovascular health. Rev Esp Cardiol. 2014;67(9):738-747.

63. Wightman JD, Heuberger RA. Effect of grape and other berries on cardiovascular health. J Sci Food Agric. In Press 2014.

64. American Heart Association Nutrition Committee; Lichtenstein AH, Appel LJ, et al. Diet and lifestyle recommendations revision 2006 A scientific statement from the American Heart Association nutrition committee. Circulation. 2006;114(1):82-96.

65. Sowers JR. Obesity as a cardiovascular risk factor. Am J Med. 2003;115(8):37-41.

66. Janghorbani M, Amini M, Willett WC, et al. First nationwide survey of prevalence of overweight, underweight, and abdominal obesity in Iranian adults. Obesity. 2007;15(11):2797-2808.

67. Amani R. Comparison between bioelectrical impedance analysis and body mass index methods in determination of obesity prevalence in Ahvazi women. Eur J Clin Nutr. 2006;61(4):478-482.

68. Ba S, JC S, WPT J. Diet, nutrition and the prevention of excess weight gain and obesity. Public Health Nutr. 2004;7(1a):123-146.

69. Amani R, Sharifi N. Cardiovascular disease risk factors. In: Gaze D, editor. The Cardiovascular System-Physiology, Diagnostics and Clinical Implications. Rijeka: InTech; 2012:978-983.

70. Victora CG, Adair L, Fall C, et al. Maternal and child undernutrition: consequences for adult health and human capital. Lancet. 2008;371(9609):340-357.

71. Osmond C, Barker D. Fetal, infant, and childhood growth are predictors of coronary heart disease, diabetes, and hypertension in adult men and women. Environ Health Perspect. 2000;108(Suppl 3):545.

72. Barker DJ. Maternal nutrition, fetal nutrition, and disease in later life. Nutrition. 1997;13(9):807-813.

73. Sheikholeslam R, Naghavi M, Abdollahi Z, et al. Current status and the 10 years trend in the malnutrition indexes of children under 5 years in Iran. Iran J Epidemiol. 2008;4(1):21-28.
74. Jafari F, Eftekhar H, Pourreza A, Mousavi J. Socio-economic and medical determinants of low birth weight in Iran: 20 years after establishment of a primary healthcare network. Public Health. 2010;124(3): $153-158$.

75. Amani R. Assessment of the rate of low birthweight and its related factors in Ahvaz, Iran, in 1995 and 1996. Food Nutr Bull. 2000;21(3): 290-292.

76. Ebbeling CB, Pawlak DB, Ludwig DS. Childhood obesity: public-health crisis, common sense cure. Lancet. 2002;360(9331):473-482.

77. Kelishadi R, Ardalan G, Gheiratmand R, et al; Caspian Study Group. Thinness, overweight and obesity in a national sample of Iranian children and adolescents: CASPIAN Study. Child Care Health Dev. 2008;34(1):44-54.

78. Kelishadi R, Hashemi Pour M, Sarraf-Zadegan N, Ansari R, Alikhassy H, Bashardoust N. Obesity and associated modifiable environmental factors in Iranian adolescents: Isfahan Healthy Heart Program - heart health promotion from childhood. Pediatr Int. 2003;45(4):435-442.

79. Gordon-Larsen P, Nelson MC, Page P, Popkin BM. Inequality in the built environment underlies key health disparities in physical activity and obesity. Pediatrics. 2006;117(2):417-424.

80. Ebadi F, Saeednia E. Food balance sheet of IR. In: Palooj M, editor. Iran 2001-2006: Overview of the Production and Distribution of Macronutrients and Micronutrients in Food. Tehran, Iran: Institute for Planning and Agricultural Economics; 2008.

81. Fakhrzadeh H, Ghotbi S, Pourebrahim R, et al. Total plasma homocysteine, folate, and vitamin b12 status in healthy Iranian adults: the Tehran homocysteine survey (2003-2004)/a cross-sectional population based study. BMC Public Health. 2006;6(1):29.

82. Strain J, Dowey L, Ward M, Pentieva K, McNulty H. B-vitamins, homocysteine metabolism and CVD. Proc Nutr Soc. 2004;63(4):597-604.

83. Hashemipour S, Larijani B, Adibi H, et al. Vitamin D deficiency and causative factors in the population of Tehran. BMC Public Health. 2004;4(1):38.

84. Hovsepian S, Amini M, Aminorroaya A, Amini P, Iraj B. Prevalence of vitamin D deficiency among adult population of Isfahan city, Iran. J Health Popul Nutr. 2011;29(2):149-155.

85. Neyestani TR, Hajifaraji M, Omidvar N, et al. High prevalence of vitamin D deficiency in school-age children in Tehran, 2008: a red alert. Public Health Nutr. 2012;15(2):324-330.

86. Wang TJ, Pencina MJ, Booth SL, et al. Vitamin D deficiency and risk of cardiovascular disease. Circulation. 2008;117(4):503-511.

87. Pittas AG, Dawson-Hughes B. Vitamin D and diabetes. J Steroid Biochem Mol Biol. 2010;121(1):425-429.

88. Ford ES, Ajani UA, McGuire LC, Liu S. Concentrations of serum vitamin D and the metabolic syndrome among US adults. Diabetes Care. 2005;28(5):1228-1230.

89. Riek AE, Oh J, Darwech I, Moynihan CE, Bruchas RR, BernalMizrachi C. $25(\mathrm{OH})$ vitamin D suppresses macrophage adhesion and migration by downregulation of ER stress and scavenger receptor A1 in type 2 diabetes. J Steroid Biochem Mol Biol. 2014; 144(pt A):172-179.

90. Heravifard S, Neyestani TR, Nikooyeh B, et al. Regular consumption of both vitamin D- and calcium- and vitamin D-fortified yogurt drink is equally accompanied by lowered blood lipoprotein (a) and elevated apoprotein $\mathrm{A} 1$ in subjects with type 2 diabetes: a randomized clinical trial. J Am Coll Nutr. 2013;32(1):26-30.

91. Sharifi N, Amani R, Hajiani E, Cheraghian B. Does vitamin D improve liver enzymes, oxidative stress, and inflammatory biomarkers in adults with non-alcoholic fatty liver disease? A randomized clinical trial. Endocrine. 2014;47(1):70-80.

92. Zittermann A. Vitamin D and cardiovascular disease. Anticancer Res. 2014;34(9):4641-4648.

93. Mozaffarian D, Aro A, Willett WC. Health effects of trans-fatty acids: experimental and observational evidence. Eur J Clin Nutr. 2009;63 (2):S5-S21. 


\section{Publish your work in this journal}

Nutrition and Dietary Supplements is an international, peer-reviewed, open access journal focusing on research into nutritional requirements in health and disease, impact on metabolism and the identification and optimal use of dietary strategies and supplements necessary for normal growth and development. The journal welcomes papers covering original research, basic science, clinical \& epidemiological studies, reviews and evaluations, guidelines, expert opinion and commentary, case reports and extended reports. The manuscript management system is completely online and includes a very quick and fair peer-review system, which is all easy to use.

Submit your manuscript here: http://www.dovepress.com/nutrition-and-dietary-supplements-journal 